\title{
Bile acids activate ryanodine receptors in pancreatic acinar cells via a direct allosteric mechanism
}

\author{
Nikolett Geyer ${ }^{\mathrm{a}}$, Gyula Diszházi ${ }^{\mathrm{a}}$, László Csernoch ${ }^{\mathrm{a}}$, István Jóna ${ }^{\mathrm{a}, \mathrm{b}}$, János Almássy ${ }^{\mathrm{a}, \mathrm{b}, *}$ \\ a Department of Physiology, University of Debrecen, Faculty of Medicine, 98. Nagyerdei krt. PO Box: 22, Debrecen 4012, Hungary \\ ${ }^{\mathrm{b}}$ Research Center for Molecular Medicine, University of Debrecen, Faculty of Medicine, 98. Nagyerdei krt. PO Box: 72, Debrecen 4012, Hungary
}

\section{A R T I C L E I N F O}

\section{Article history:}

Received 22 December 2014

Received in revised form 10 March 2015

Accepted 30 March 2015

Available online $\mathrm{xxx}$

\section{Keywords:}

Ryanodine receptor

SERCA

Calcium release

Pancreas

Pancreatitis

Bile acid

\begin{abstract}
A B S T R A C T
The earliest critical event of pancreatitis is a long lasting high amplitude rise of intracellular $\mathrm{Ca}^{2+}$ concentration of the acinar cell, which can be triggered by high concentration of bile acids. Although, $\mathrm{Ca}^{2+}$-release through ryanodine receptors (RyR) is involved in the process, the significance and the exact mechanism of bile acid's action on RyR has not been fully elucidated yet. Therefore, we aimed to test with various techniques and aspects whether bile acids exert a direct effect on RyR and SERCA pump.

Our data show that taurocholic acid (TCA)-induced $\mathrm{Ca}^{2+}$ release in pancreatic acinar cells was significantly reduced by the RyR antagonist dantrolene. Further, we show that TCA enhanced RyR's ${ }^{3} \mathrm{H}$-ryanodine binding and triggered robust $\mathrm{Ca}^{2+}$-release from RyR-enriched vesicles in the pathologically relevant concentration range. RyR single channel current analysis demonstrated that $200 \mu \mathrm{M}$ TCA induced a 5-fold increase in the channel's open probability and caused a significant lengthening of the mean open time. TCA also suppressed $\mathrm{Ca}^{2+}$-uptake rate and ATP-ase activity of SERCA-enriched vesicles, but interestingly, failed to decrease $\mathrm{Ca}^{2+}$ elimination rate in intact cells.

Overall, our results strongly suggest that TCA opens RyR by an allosteric mechanism, which contribute significantly to bile acid-induced pathologic $\mathrm{Ca}^{2+}$-leak from the endoplasmic reticulum in pancreatic acinar cells.
\end{abstract}

(c) 2015 Published by Elsevier Ltd.

\section{Introduction}

Pancreatitis is a painful and potentially fatal inflammatory disease with a high incidence rate of around 13-45/100,000 people/year [1]. Specific medical therapies are not available. The most common cause of pancreatitis are gallstones, which cause reflux of the bile into the pancreatic duct system by occluding the common bile duct $[2,3]$. Bile acid concentration therefore may reach millimolar levels in the pancreas, which triggers uncontrolled $\mathrm{Ca}^{2+}$

Abbreviations: RyR, ryanodine receptor; $\left[\mathrm{Ca}^{2+}\right] \mathrm{i}$, intracellular $\mathrm{Ca}^{2+}$ concentration; $\mathrm{IP}_{3} \mathrm{R}$, inositol trisphosphate receptor; ER, endoplasmic reticulum; TC, terminal cisternae; LSR, longitudinal sarcoplasmic reticulum; $\mathrm{CICR}, \mathrm{Ca}^{2+}$ induced $\mathrm{Ca}^{2+}$ release; SERCA, sarco-endoplasmic reticulum $\mathrm{Ca}^{2+}$ pump; TLCS, taurolitocholic acid-3sulphate; TCA, taurocholate; TDC, taurodeoxycholate; CPA, cyclopiazonic acid; RR, ruthenium red; Po, open probability; FWHM, full widths at half maximum; cch carbachol.

* Corresponding author at: Department of Physiology, University of Debrecen, Faculty of Medicine, 98. Nagyerdei krt. PO Box: 22, Debrecen 4012, Hungary. Tel.: +36 304331450

E-mail addresses: geyer.nikoletta@med.unideb.hu (N. Geyer), diszigyuszi@gmail.com (G. Diszházi), csl@edu.unideb.hu (L. Csernoch), jona.istvan@med.unideb.hu (I. Jóna), almassy.janos@med.unideb.hu (J. Almássy). release and prolonged elevation of the intracellular $\mathrm{Ca}^{2+}$ concentration $\left(\left[\mathrm{Ca}^{2+}\right] \mathrm{i}\right)$ in the acinar cell [4]. Impaired $\mathrm{Ca}^{2+}$ signaling is considered to be the critical molecular step of acute pancreatitis because it causes premature intraacinar protease activation and acinar cell damage that provokes the inflammation [5,6].

During physiological pancreatic acinar cell stimulation, exocytosis of zymogens is controlled by $\mathrm{Ca}^{2+}$ oscillations highly localized to the apical region of the cell [7]. The spatial localization of $\mathrm{Ca}^{2+}$ release is explained by high inositol trisphosphate receptor $\left(\mathrm{IP}_{3} \mathrm{R}\right)$ density in the apical endoplasmic reticulum (ER) (also called $\mathrm{Ca}^{2+}$ release trigger zone) [8,9]. In contrast, overstimulation of the pancreatic acinar cell by secretagouges and high concentrations of bile acids induce whole-cell, high amplitude, long lasting, (peak-plateau type) $\mathrm{Ca}^{2+}$ signals. The mechanism underlying global $\mathrm{Ca}^{2+}$ signals is $\mathrm{Ca}^{2+}$ wave propagation, which involves the $\mathrm{Ca}^{2+}$ dependent activation of ryanodine receptor (RyR) $\mathrm{Ca}^{2+}$ release channels that show higher density in the basolateral-supranuclear region of the acinar cell. Since the ryanodine sensitive compartment is the major source of $\mathrm{Ca}^{2+}$ under pathological $\mathrm{Ca}^{2+}$ release, the role of RyR in the pathomechanism seems to be essential $[4,10,11]$. For instance, recent studies showed that $\mathrm{Ca}^{2+}$ signals in the basolateral areas induced by supramaximal concentrations of carbachol and that of 
the subcellular distribution of RyR overlapped with the regions where caerulein-induced early zymogen activation occurred [10]. More importantly, the RyR inhibitor dantrolene diminished the carbachol-induced $\left[\mathrm{Ca}^{2+}\right]$ i elevation selectively in the basolateral region and reduced the severity of experimental pancreatitis in vivo [11]. These data provide strong evidence that RyR plays a significant role in the pathomechanism of pancreatitis and therefore it can be considered as an important therapeutic target.

The bile acid taurolitocholic acid-3-sulphate (TLCS) was also demonstrated to produce global $\mathrm{Ca}^{2+}$ release, which originated in the apical region and spread toward the basal end of the acinar cell [5]. In permeabilized cell assay, bile acid retained its effect when $\mathrm{IP}_{3} \mathrm{R}$ or RyR were blocked, but failed when both $\mathrm{IP}_{3} \mathrm{R}$ and RyRs were inhibited [12]. Moreover, both dantrolene and ryanodine converted bile acid-induced sustained intracellular $\left[\mathrm{Ca}^{2+}\right]$ elevations to physiological $\mathrm{Ca}^{2+}$ oscillations in intact cells [4]. Although, these data suggest that bile acids trigger excessive $\mathrm{Ca}^{2+}$ release by directly opening RyRs too, this possibility remains to be tested, because alternatively, RyR might be activated indirectly via $\mathrm{Ca}^{2+}$ induced $\mathrm{Ca}^{2+}$ release (CICR) mechanism by the $\mathrm{Ca}^{2+}$, released from acidic vesicles through NAADP receptor $\mathrm{Ca}^{2+}$ channels $[6,12]$. Nevertheless, this question has not been addressed yet. Furthermore, bile acids were reported to inhibit sarco-endoplasmic reticulum $\mathrm{Ca}^{2+}$ pump's (SERCA) activity which might result in an increased RyR and $\mathrm{IP}_{3} \mathrm{R}$ mediated $\mathrm{Ca}^{2+}$ leak and CICR rate [13].

As pictured above, despite the fact that bile acid-induced $\mathrm{Ca}^{2+}$ signals in pancreatic acinar cells are intensively studied, the complex interplay between the $\mathrm{Ca}^{2+}$ transporters makes the role of RyR and SERCA difficult to evaluate in this process. Therefore, we aimed to test the action of different bile acids explicitly on RyR and SERCA function using the most direct methods available and in the simplest settings possible.

The major components of the bile, cholate and chenodeoxycholate are synthesized by the liver and converted to secondary bile acids including taurocholate, deoxycholate and lithocholates by the intestinal flora. Due to secondary bile acid recycling through the enterohepatic circulation, bile acids occur in taurin-conjugated form. Because taurine conjugated bile acids are the most effective $\mathrm{Ca}^{2+}$ mobilizers among bile acids, the major taurin-conjugated bile acid taurocholic acid's (TCA) effect was tested throughout the study. In addition, other secondary bile acids taurodeoxycholate (TDC) and taurolitocholic acid sulphate (TLCS) have also been tested in $\mathrm{Ca}^{2+}$ imaging and $\mathrm{Ca}^{2+}$ release assays. In order to selectively investigate RyR's or SERCA function, ${ }^{3} \mathrm{H}$ ryanodine binding assay, $\mathrm{Ca}^{2+}$ release measurements, single channel recording, and an enzymelinked NADH assay were performed using purified microsomes. These experiments all demonstrate that bile acids are potent RyR openers and SERCA inhibitors.

\section{Material and methods}

\subsection{Chemicals}

If not specified, chemicals were purchased from Sigma.

\subsection{Pancreatic acinar cell isolation}

Pancreatic acinar cells were freshly isolated from mouse pancreas as described previously [14]. Briefly, 4 months old NMRI mice of both genders were sacrificed by cervical dislocation and the pancreas was removed. The tissue was injected with F12/DMEM medium containing $100 \mathrm{U} / \mathrm{ml}$ collagenase $\mathrm{P}$ (Roche), $0.1 \mathrm{mg} / \mathrm{ml}$ trypsin inhibitor and $2.5 \mathrm{mg} / \mathrm{ml} \mathrm{BSA}$, then incubated in this solution in a $37^{\circ} \mathrm{C}$ shaking water bath for $30 \mathrm{~min}$, and continuously gassed with carbogen. The tissue was dissociated by pipetting with a serological pipette 4-6 times, then filtered through mesh \#60 $(150 \mu \mathrm{m})$. Cells were layered on the top of $400 \mathrm{mg} / \mathrm{ml} \mathrm{BSA}$ and washed through the medium by gentle centrifugation. The pellet was resuspended in saline solution, collected by centrifugation. Acinar cell clumps were gently resuspended in F12/DMEM medium and kept gassed at room temperature until use.

\subsection{Intracellular $\mathrm{Ca}^{2+}$ imaging}

Acinar cell clumps were loaded with $2 \mu \mathrm{M}$ Fluo- $4 \mathrm{AM} \mathrm{Ca}^{2+}$ sensitive dye for $30 \mathrm{~min}$ at room temperature. Acinar cells were plated on glass coverslips and mounted on a perfusion chamber. After perfusion with $\mathrm{Ca}^{2+}$-free Tyrode's solution containing (in $\mathrm{mM}$ ): $140 \mathrm{NaCl}, 5 \mathrm{KCl}, 2 \mathrm{MgCl}$ and 10 HEPES, $\mathrm{pH} 7.2$, taurocholate (1, 2 or $5 \mathrm{mM})$, tauro deoxycholate $(1 \mathrm{mM})$ or taurolythocholic acid sulphate $(0.25 \mathrm{mM})$ was applied by superfusing the cells for 3 or 12 min at room temperature. At the end of each measurement, $2 \mu \mathrm{M}$ carbachol was applied to obtain an internal control signal. In some experiments, the loading and imaging media was supplemented with $12 \mu \mathrm{M}$ dantrolene or $1.8 \mathrm{mM} \mathrm{CaCl}_{2}$.

Fluorescence was monitored using a Zeiss LSM 5 LIVE confocal microscope equipped with a $40 \times$ objective. Fluo- 4 was excited at $488 \mathrm{~nm}$ and the emitted light was collected through a $520 \mathrm{~nm}$ filter. Fluorescence emission data of single cells was analyzed and F/FO ratio was calculated after background subtraction using Zeiss ZEN 2009 software. Data were averaged from multiple cells in each experiment then, these values were further averaged to get the mean \pm SEM.

\subsection{Microsome isolation}

Microsomes from rat pancreas were isolated as described earlier [15]. A pancreas was homogenized using a glass homogenizer in $6 \mathrm{ml}$ ice cold DMEM supplemented with Roche protease inhibitor cocktail. The homogenate was transferred into $1.5 \mathrm{ml}$ microcentrifuge tubes and centrifuged at $11,000 \times g$ for $15 \mathrm{~min}$ The fluffy layer on the top of the pellet was collected and centrifuged at $240,000 \times \mathrm{g}$ in a sw 55 ti rotor for $30 \mathrm{~min}$ at $4{ }^{\circ} \mathrm{C}$. The pellet was resuspended in a small volume of $300 \mathrm{mM}$ sucrose, $10 \mathrm{mM}$ K-PIPES $(\mathrm{pH}=7.0)$, rapidly frozen in liquid nitrogen and stored at $-70^{\circ} \mathrm{C}$.

Sarcoplasmic reticulum terminal cisternae (TC)- and longitudinal SR (LSR) vesicles were isolated from $50 \mathrm{~g}$ of rabbit skeletal muscle by differential centrifugation as described previously [16]. All the steps were carried out in cold room or on ice and in the presence of protease inhibitors (in $\mu \mathrm{M}$ : 200 pefabloc SC, 0.1 aprotinin, 1 leupeptin, 0.2 pepstatin A, 500 benzamidine). After homogenization in $450 \mathrm{ml}$ buffer (in mM: $100 \mathrm{NaCl}, 20$ EGTA, $20 \mathrm{Na}$-HEPES, $\mathrm{pH}=7.5$ ), cell debris was pelleted at $3500 \times \mathrm{g}$, for $35 \mathrm{~min}$ using a tabletop centrifuge equipped with a swing-out rotor. Crude microsomes were collected from the supernatant by centrifugation in a Ti45 rotor at $40,000 \times g$, for 30 min To dissolve the actomyosin content the pellet was resuspended in (in $\mathrm{mM}$ ) $600 \mathrm{KCl}, 10 \mathrm{~K}-\mathrm{Pipes}$, 250 sucrose, 1 EGTA, $0.9 \mathrm{CaCl}_{2}$ (pH, 7.0). After incubation for $1 \mathrm{~h}$ at $4{ }^{\circ} \mathrm{C}$, the microsome fraction was centrifuged at $109,000 \times \mathrm{g}$, for $30 \mathrm{~min}$, the pellet was resuspended and loaded onto a $20-45 \%$ linear sucrose gradient (in mM: $105 \mathrm{NaCl}, 10$ Pipes, 0.1 EGTA, 0.09 $\mathrm{CaCl}_{2}, \mathrm{pH}=7.0$ ). After spinning overnight at $90,000 \times \mathrm{g}$ in a SW27 rotor, two visible rings, corresponding to LSR and TC vesicles were collected from the $30-32 \%$ and the $36-38 \%$ regions of the sucrose gradient, respectively. The microsomes were washed with a buffer, containing (in mM) 475 sucrose, $1 \mathrm{NaCl}, 10$ Pipes ( $\mathrm{pH}=7.0)$ and pelleted by centrifugation at $124,000 \times g$ for $60 \mathrm{~min}$ in a Ti45 rotor. The pellet was resuspended at a final protein concentration of $>20 \mathrm{mg} / \mathrm{ml}$ in a solution containing $300 \mathrm{mM}$ sucrose and $10 \mathrm{mM} \mathrm{K}$ PIPES $(\mathrm{pH}=7.0)$. Vesicles were aliquoted and rapidly frozen in liquid nitrogen and stored at $-70^{\circ} \mathrm{C}$ until further use or were immediately 
used for RyR purification. Because the LSR fraction is more abundant in SERCA pump than TC, but does not contain RyR, it was used in $\mathrm{Ca}^{2+}$ uptake- and in ATPase activity measurements. TC microsomal fraction contains both RyR and SERCA pump, so they are used in $\mathrm{Ca}^{2+}$ release assays and for RyR purification. Importantly, these skeletal muscle microsomal fractions do not contain $\mathrm{IP}_{3} \mathrm{Rs}$.

\subsection{RyR purification}

TC vesicles ( $3 \mathrm{mg}$ protein $/ \mathrm{ml}$ ) were solubilized for $2 \mathrm{~h}$ in a buffer containing $1 \%$ CHAPS, $1 \mathrm{M} \mathrm{NaCl}, 100 \mu \mathrm{M}$ EGTA, $150 \mu \mathrm{M} \mathrm{CaCl} 2$, $5 \mathrm{mM}$ AMP, $0.45 \%$ phosphatidylcholine, $20 \mathrm{mM}$ Na-PIPES ( $\mathrm{pH}=7.2$ ) at $4{ }^{\circ} \mathrm{C}$. The sample was loaded onto a $10-28 \%$ linear sucrose gradient and centrifuged overnight at $90,000 \times g$ in a SW27 rotor. In order to detect RyR in the sucrose gradient, a small portion of the sample was labeled with ${ }^{3} \mathrm{H}$ ryanodine during solubilization. RyRcontaining fractions were identified, aliquoted, snap-frozen and stored at $-70^{\circ} \mathrm{C}$ until use [16].

\section{6. ${ }^{3}$ H ryanodine binding assay}

Equilibrium ryanodine-binding assay was carried out using ${ }^{3} \mathrm{H}$ ryanodine in a medium composed of (in $\mathrm{mM}$ ) $130 \mathrm{NaCl}, 20 \mathrm{Na} / \mathrm{PIPES}$ pH 7.1, 1 Pefabloc SC. The desired ionized $\mathrm{Ca}^{2+}$ concentrations were adjusted with EGTA [17-19]. Aliquots $(32 \mu \mathrm{l})$ containing $16 \mu \mathrm{g}$ protein were incubated at $37^{\circ} \mathrm{C}$ for $120 \mathrm{~min}$, with various concentrations of radioligand, as indicated in the figure legends. The reaction was terminated by filtering the samples using a BIODOT 96-well filter apparatus and $0.45 \mu \mathrm{m}$ nitrocellulose membrane (Millipore). After filtration, the membrane was washed with equal aliquots of washing medium. The washing buffer was identical to the incubation medium except that ryanodine and $\mathrm{Ca}^{2+}$ was omitted. Nonspecific binding was determined in the presence of $1000 \times$ excess of ryanodine, which had been added to the incubation mixture prior to the radioligand [20]. The membrane was cut into appropriate pieces and their radioactivity was determined using a liquid scintillation counter (Packard Tri-Carb) [21].

\subsection{Calcium flux- and uptake measurements}

TC vesicles were actively loaded with $\mathrm{Ca}^{2+}$ in the cuvette at $37^{\circ} \mathrm{C}$ by the addition of the appropriate amount of $\mathrm{CaCl}_{2}$ in the solution containing (in $\mathrm{mM}$ ) $92.5 \mathrm{KCl}, 18.5 \mathrm{MOPS}, 1 \mathrm{MgCl}_{2}, 1$ ATP, $\mathrm{pH}=7.0$. In each experiment, $0.5 \mathrm{mg}$ protein was used. Calcium efflux was determined by measuring the extravesicular $\left[\mathrm{Ca}^{2+}\right]$ using the metallochromic dye antipyrylazo III $(250 \mu \mathrm{M})$. Transmittance was monitored by a spectrofluorimeter (Spex Fluoromax) at $710 \mathrm{~nm}$. The rate of $\mathrm{Ca}^{2+}$ release was obtained by measuring the slope of the initial segment of the process [16]. Absorbance was calculated off-line and was normalized to the average of the first 5 data points. In some experiments vesicles were pretreated with $12 \mu \mathrm{M}$ dantrolene 30 min prior to be suspended in the imaging solution, which was also supplemented with dantrolene.

$\mathrm{Ca}^{2+}$ uptake rate of $250 \mu \mathrm{g}$ longitudinal sarcoplasmic reticulum vesicles (LSR) was assessed by measuring the slope of absorbance change following an addition of $\mathrm{Ca}^{2+}$ under control conditions or in the presence of $250 \mu \mathrm{M}$ TCA. To inhibit leak through RyRs in these experiments, $5 \mu \mathrm{M}$ ruthenium red was included into the solution.

\subsection{RyR reconstitution and single-channel current recording}

Measurements of channel activity were carried out using purified RyR incorporated into planar lipid bilayers [16]. Bilayers were formed in a symmetrical buffer solution $(250 \mathrm{mM} \mathrm{KCl}$, $100 \mu \mathrm{M} \mathrm{K}_{2} \mathrm{H}_{2}$ EGTA, $150 \mu \mathrm{M} \mathrm{CaCl}_{2}, 20 \mathrm{mM}$ HEPES, pH 7.2), across a $200 \mu \mathrm{m}$ wide hole drilled into the wall of a delrin cap. The bilayer chamber was manufactured by Warner Instruments Inc. (Hamden, CT, U.S.A.). The lipid mixture contained phosphatidylethanolamine, phosphatidylserine, and phosphatidylcholine in the ratio of $5: 4: 1$ dissolved in $n$-decane in the final lipid concentration of $20 \mathrm{mg} / \mathrm{ml}$. The lipids were obtained from Avanti Polar Lipids.

RyR fusion with the bilayer was induced by the addition of a small aliquot of purified RyR into the chamber, which was defined as cis (cytoplasmic) side. The other chamber was referred to trans (luminal) and was kept on ground potential. After successful incorporation of RyR, free $\left[\mathrm{Ca}^{2+}\right]$ in the cis chamber was decreased from $50 \mu \mathrm{M}$, to $270 \mathrm{nM}$ by the addition of EGTA. Then, TCA was applied to the cytoplasmic side of the RyR. The experiments were performed at a membrane potential of +60 or $-60 \mathrm{mV}$. The holding potential of the membrane was adjusted, and the bilayer currents were recorded using an Axopatch 200 amplifier and pCLAMP 6.03 software (Axon Instruments, Foster City, CA, U.S.A.). Currents were filtered at $1 \mathrm{kHz}$ through an eight-pole lowpass Bessel filter and digitized at $3 \mathrm{kHz}$. Open probabilities and mean open times were calculated with clampfit 10 software.

\subsection{ATPase activity measurements}

ATPase activity of LSR vesicles was determined at $37^{\circ} \mathrm{C}$ by a coupled enzyme assay in a medium containing (in $\mathrm{mM}$ ) $100 \mathrm{KCl}$, 20 Tris- $\mathrm{HCl}, 5 \mathrm{MgCl}_{2}$, 5 ATP, 0.42 phosphoenolpyruvate, 0.001 calcimycin (A23187, a Ca ${ }^{2+}$ ionophore), 0.2 NADH, 7.5 U/ml pyruvate kinase, and $18 \mathrm{U} / \mathrm{ml}$ lactate dehydrogenase ( $\mathrm{pH} 7.5$ ). The assay was performed at free $\left[\mathrm{Ca}^{2+}\right]$ of $1 \mu \mathrm{M}$ to allow maximum SERCA activity. Calcimycin was applied to prevent accumulation of $\mathrm{Ca}^{2+}$ in the vesicles (i.e. end-product inhibition). LSR was obtained as described above from rabbit skeletal muscle and the protein concentration was $5.5 \mu \mathrm{g} / \mathrm{ml}$ in each experiment [22]. Total hydrolytic activity was measured as the decrease of optical density at the NADH absorbance wavelength $(340 \mathrm{~nm})$ and expressed in micromoles of inorganic phosphate per milligrams of protein per minute (abbreviated as I.U.) [16]. TCA was added to the medium $1 \mathrm{~min}$ before starting the enzyme activity measurements.

\subsection{Statistical analysis}

Analysis was made in Origin 7.0 (Microcal Software, Northampton, MA, USA) or in Microsoft Excel. Data are presented as the average of at least three independent experiments ( $n$, number of experiments or cells measured). Averages are expressed as mean \pm SEM (standard error of the mean). Statistical analysis was performed by using Student's $t$-test. Threshold for statistically significant differences as compared to the respective control was set at ${ }^{*} p<0.05$.

The number of experiments are expressed as $n=$ number of experimental repeats/total number of cells/responding cells.

\section{Results}

\subsection{Intracellular calcium imaging}

Our first series of experiments were performed to reproduce previous results and to further investigate the role of RyR in pancreatic acinar cells' intracellular $\mathrm{Ca}^{2+}$ signaling. To this end, Fluo-4 fluorescence data was collected from enzymatically isolated pancreatic acinar cell clumps. A bright field image of a typical cell group used in this work is shown in the top image of Fig. 1, which illustrates that polarized apical secretory granule localization is retained after the isolation.

In order to selectively investigate $\mathrm{Ca}^{2+}$ release from the intracellular compartments and to avoid $\mathrm{Ca}^{2+}$ entry from the extracellular space, cells were bathed in a $\mathrm{Ca}^{2+}$-free saline solution throughout 

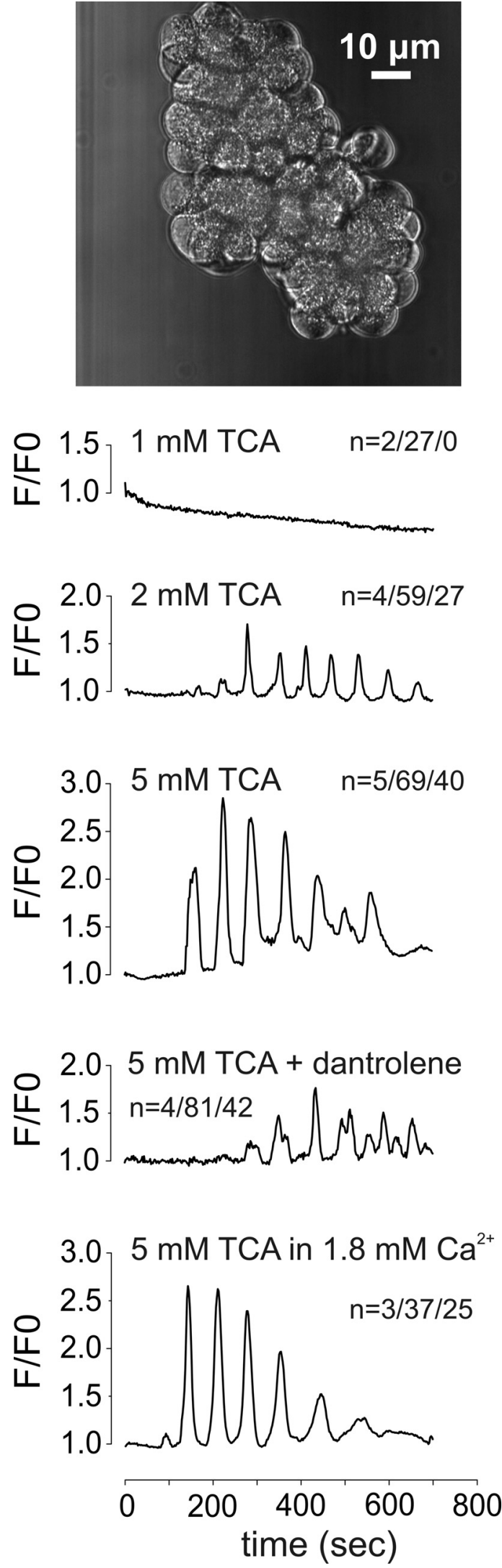

Fig. 1. Taurocholic acid triggers $\mathrm{Ca}^{2+}$ release in pancreatic acinar cells. $\mathrm{Ca}^{2+}$ imaging was performed on enzymatically isolated mouse pancreatic acinar cells loaded with Fluo-4 AM. An example of an acinar cell clump is shown in the top image. Cells were bathed in $\mathrm{Ca}^{2+}$-free physiological saline solution and treated with 1,2 , and $5 \mathrm{mM}$ taurocholic acid (TCA) for $12 \mathrm{~min}$. Further experiments were performed in $1.8 \mathrm{mM} \mathrm{Ca}^{2+}$ and in the presence of $12 \mu \mathrm{M}$ dantrolene. Examples of normalized the whole experiment. Examples of such experiments are illustrated in Fig. 1. Cells were treated with 1,2 and 5 mM TCA for 12 min, respectively. $1 \mathrm{mM}$ TCA failed to trigger $\mathrm{Ca}^{2+}$ release, whereas 2 and $5 \mathrm{mM}$ TCA induced repetitive $\left[\mathrm{Ca}^{2+}\right]$ i oscillations. The effect of TCA was concentration dependent: $5 \mathrm{mM}$ TCA induced significantly higher amplitude of $\mathrm{Ca}^{2+}$-spikes, with earlier onset compared to $1 \mathrm{mM}$. The first spike developed approximately 3 min after cells have been started to be perfused with the bile acid. The lazy development of the effect can probably be attributed to the relatively slow transport rate of carrier mediated bile acid transporters. We never observed a sustained response, however, in some way the fact that (at $5 \mathrm{mM} \mathrm{TCA}$ ) the baseline between the spikes tends to increase in about $38 \%$ of the cells can be interpreted as progressive $\mathrm{Ca}^{2+}$ accumulation. The effect of $5 \mathrm{mM}$ TCA was also tested in $1.8 \mathrm{mM}$ extracellular $\mathrm{Ca}^{2+}$. Apparently, the presence of extracellular $\mathrm{Ca}^{2+}$ did not change the features of the $\mathrm{Ca}^{2+}$ signals (bottom trace). These data are in agreement with previous studies using TCA at the same concentrations for the same period of time [5]. Because, we were interested in the role of RyR in TCA-triggered $\mathrm{Ca}^{2+}$ release, we also tested the effect of the RyR inhibitor dantrolene. The fourth trace in Fig. 1 shows a representative record of a cell treated with $5 \mathrm{mM}$ TCA together with $12 \mu \mathrm{M}$ dantrolene in a $\mathrm{Ca}^{2+}$-free solution. These raw data imply that dantrolene significantly inhibited the amplitude of $\left[\mathrm{Ca}^{2+}\right]$ spikes through the whole length of TCA application.

Quantitative analysis of the effect of dantrolene was performed on experimental data, when $5 \mathrm{mM}$ TCA was applied for $3 \mathrm{~min}$. This treatment resulted in a single $\mathrm{Ca}^{2+}$-transient (Fig. 2A). In order to assess the contribution of RyRs to $\mathrm{Ca}^{2+}$ release, cells were also treated with the RyR antagonist dantrolene before and during TCA application (Fig. 2B). At the end of each experiment, supramaximal dose $(2 \mu \mathrm{M})$ of the parasympathomimetic drug carbachol (cch) was applied to induce maximal $\mathrm{Ca}^{2+}$ response. During data analysis, this cch-induced peak-fluorescence was used as a reference value to quantify the relative amplitude of the TCA-signal. In Fig. 2C, pooled data of TCA and cch induced $\mathrm{Ca}^{2+}$-signal peak ratios of 39 and 27 cells are shown under control conditions (TCA-only) and in the presence of dantrolene, respectively. These results demonstrate that $12 \mu \mathrm{M}$ dantrolene significantly suppressed the relative magnitude of the TCA-induced acinar cell response from $0.6 \pm 0.08$ to $0.29 \pm 0.08$, but essentially the same proportion of cells responded (30 vs. 34\%). The average peak latency was $195 \pm 5 \mathrm{~s}$ which slightly shifted to $210 \pm 3.9 \mathrm{~s}$ in the dantrolene treated cells. These data confirm earlier observations implying that RyR plays a significant role in bile acid-induced $\left[\mathrm{Ca}^{2+}\right]$ transients. Next, using more direct methods we tested whether bile acids may act on RyRs.

\subsection{Taurocholic acid enhances ${ }^{3} \mathrm{H}$ ryanodine binding to microsomes}

To investigate TCA's action on RyR activity under more dissected conditions, next, we used pancreas microsomes in a radiolabeled ${ }^{3} \mathrm{H}$ ryanodine binding assay. The assay utilizes the feature of ryanodine that it binds to RyR in a use-dependent and irreversible manner. Therefore, the quantity of ${ }^{3} \mathrm{H}$ ryanodine bound to microsomes at unit length of time is proportional to RyR's mean open probability.

First, the amount of ryanodine specifically bound to pancreatic crude microsomes was determined under control conditions and in the presence of $200 \mu \mathrm{M}$ TCA. Pancreatic microsomes showed

fluorescence-background ratios are shown. 2 and $5 \mathrm{mM}$ TCA triggered repetitive fluctuations of the fluorescence signal, which was suppressed by the ryanodine receptor antagonist dantrolene. $1 \mathrm{mM}$ TCA remained without effect during the whole application period. TCA: taurocholic acid. 


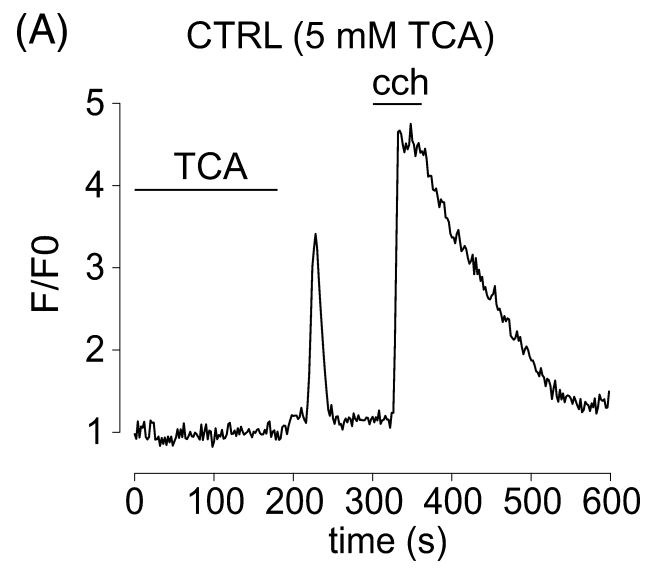

(B) dantrolene (5 mM TCA)

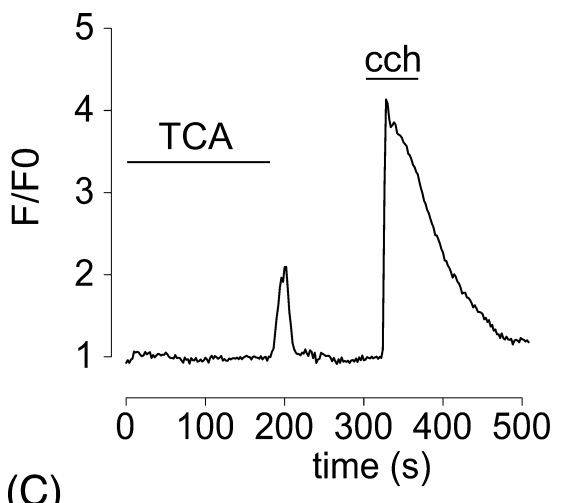

(C)

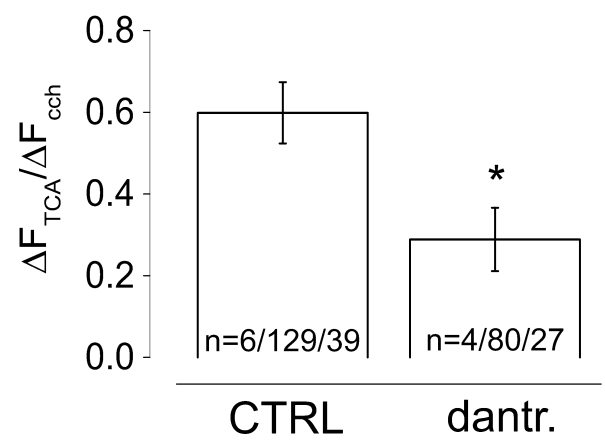

Fig. 2. Dantrolene inhibits taurocholic acid-induced $\mathrm{Ca}^{2+}$ release in pancreatic acinar cells. $\mathrm{Ca}^{2+}$ imaging was performed on enzymatically isolated mouse pancreatic acinar cells loaded with Fluo-4 AM. In order to avoid the effect of interfering $\mathrm{Ca}^{2+}$ influx mechanisms, the experiments were performed in $\mathrm{Ca}^{2+}$-free medium. The representative $\mathrm{Ca}^{2+}$ signal shown in (A) was recorded in an individual cell stimulated with $5 \mathrm{mM}$ taurocholic acid (TCA) under control conditions, while the one shown in (B) was obtained after dantrolene ( $30 \mathrm{~min}, 12 \mu \mathrm{M})$ pretreatment and in the presence of dantrolene. 3 min after TCA perfusion was started, a robust, simultaneous elevation of intracellular $\left[\mathrm{Ca}^{2+}\right]$ was observed in both cases, but in the presence of dantrolene the TCA-related fluorescence-change was significantly lower. TCA-responses were normalized to the amplitude of $\mathrm{Ca}^{2+}$ release induced by $2 \mu \mathrm{M}$ carbachol (cch), which was used at the end of each measurement as a proof of retained functionality of the cells. The normalized values for control and dantrolene treated cells are summarized in (C) $\left(n=6 / 39\right.$ and $\left.4 / 27,{ }^{*} p<0.05\right)$. TCA: taurocholic acid, cch: carbachol.

relatively small specific activity of $0.13 \pm 0.03 \mathrm{pM}$ ryanodine $/ \mathrm{mg}$ protein at physiologic $\mathrm{Ca}^{2+}$ concentration $(472 \mathrm{nM})$, which was increased by TCA treatment to $0.24 \pm 0.05$ ( $n=8$ and 9). Fig. 3A shows pooled data of three independent experiments. These data support our basic hypothesis that TCA stimulates RyR in pancreatic acinar cells. However, this approach was limited by the high background noise and low specific activity of the pancreatic sample, possibly due to the relatively low density of RyR in the pancreatic ER and the low yield of ER microsome isolation procedure.

Pancreatic acinar cells were shown to express the skeletal muscle type RyR isoform (RyR1) in PCR studies [23,11]. Our live cell Ca ${ }^{2+}$ imaging data using the RyR1 isoform specific antagonist dantrolene [24] also suggest that the primary RyR isoform in pancreatic acinar cells is the RyR type 1 . Also, because skeletal muscle microsome preparations are of higher quality and quantity source of RyR1, they make a good substitute of pancreatic microsomes. Therefore, in order to improve our measurements' signal to background ratio, skeletal muscle terminal cisternae (TC) vesicles were used as a model to test further the effect of TCA. These experiments were designed to measure ${ }^{3} \mathrm{H}$ ryanodine binding to TC vesicles using different concentrations of radiolabeled ryanodine under control conditions or in the presence of $200 \mu \mathrm{M}$ TCA and to test the $\mathrm{Ca}^{2+}$ dependence of TCA-RyR interaction in media containing $472 \mathrm{nM}$ or $5 \mu \mathrm{M} \mathrm{Ca}^{2+}$. We chose these $\left[\mathrm{Ca}^{2+}\right] \mathrm{s}$ because under our circumstances ryanodine binding is too low in the lower nanomolar range to measure accurately, whereas $5 \mu \mathrm{M}$ is around the dissociation constant for $\mathrm{Ca}^{2+}$. TCA was found to promote ${ }^{3} \mathrm{H}$ ryanodine binding to TC vesicles at both $\mathrm{Ca}^{2+}$ concentrations, as shown by Fig. $3 \mathrm{~B}$ and $\mathrm{C}$. These findings confirm the data, which were obtained with pancreatic microsomes, that TCA stimulates RyR activity and also verifies that TCA acts similarly on both preparations. Next, TCA's doseresponse relationship was determined by incubating TC vesicles along with different concentrations of TCA and $18 \mathrm{nM}^{3} \mathrm{H}$ ryanodine in a $472 \mathrm{nM}$ or $1.3 \mu \mathrm{M} \mathrm{Ca}^{2+}$ containing solutions. Specific radioactivity significantly increased even in the presence of $25 \mu \mathrm{M}$ TCA, which was further increased by higher concentrations of TCA at both $\left[\mathrm{Ca}^{2+}\right] \mathrm{s}$ (Fig. 3D and E). These results show that TCA activates RyR in the wide range of $\left[\mathrm{Ca}^{2+}\right]$, therefore bile acid action neither depends on $\left[\mathrm{Ca}^{2+}\right]$, nor use-dependent. Importantly, these results argue against the idea that bile acids trigger $\mathrm{Ca}^{2+}$ release through their ionophoretic activity on SR vesicles [25].

\subsection{TCA triggers $\mathrm{Ca}^{2+}$ efflux from $\mathrm{TC}$ vesicles}

Afterwards, $\mathrm{Ca}^{2+}$ release assay was used to further elucidate the effect of TCA on RyR. Fig. 4A shows a representative record of four independent experiments, in which extravesicular $\left[\mathrm{Ca}^{2+}\right]$ was monitored by measuring the absorbance of the metallochromic dye antipyrylazo III at $710 \mathrm{~nm}$ wavelength. In each experiment, equal quantities of TC vesicles were actively loaded with identical amounts of $\mathrm{Ca}^{2+}$ using the vesicles' SERCA pump activity and MgATP. Extravesicular $\left[\mathrm{Ca}^{2+}\right]$ was suddenly raised by two subsequent injections of small volumes of $\mathrm{Ca}^{2+}$ containing solution, which was instantly loaded into the intraluminar space by the ATPase, as reported by the rapid recovery of the absorbance. The newly established steady baseline is due to the dynamic balance between two opposing mechanisms: the intrinsic $\mathrm{Ca}^{2+}$ leak through RyRs and the $\mathrm{Ca}^{2+}$ uptake. Therefore, in order to selectively investigate RyR function, SERCA needs to be inhibited. For this reason, SERCA inhibitor cyclopiazonic acid (CPA) was added few seconds before TCA treatment. Experiments were also done with CPA alone. These records showed slow $\mathrm{Ca}^{2+}$ leak, which is due to the constant background RyR activity and the lack of SERCA activity. Therefore, they served as control. Representative records and averaged data (Fig. 4A right) clearly show that $500 \mu \mathrm{M}$ TCA triggered a significantly stronger $\mathrm{Ca}^{2+}$ efflux compared to CPA only. More importantly, incubation of TC vesicles with therapeutic concentrations $(12 \mu \mathrm{M})$ of RyR inhibitor dantrolene caused a 113 second delay in the $\mathrm{Ca}^{2+}$ efflux's latency ( $t$ was $112 \pm 15 \mathrm{~s}$ for the control and $225 \pm 31 \mathrm{~s}$ for the dantrolene treated vesicles) (Fig. 4B), whereas $20 \mu \mathrm{M}$ ryanodine prevented the TCA-induced $\mathrm{Ca}^{2+}$ release. Thus, we conclude that TCA exerts its effect specifically through RyR by a direct allosteric mechanism and it is independent of the 

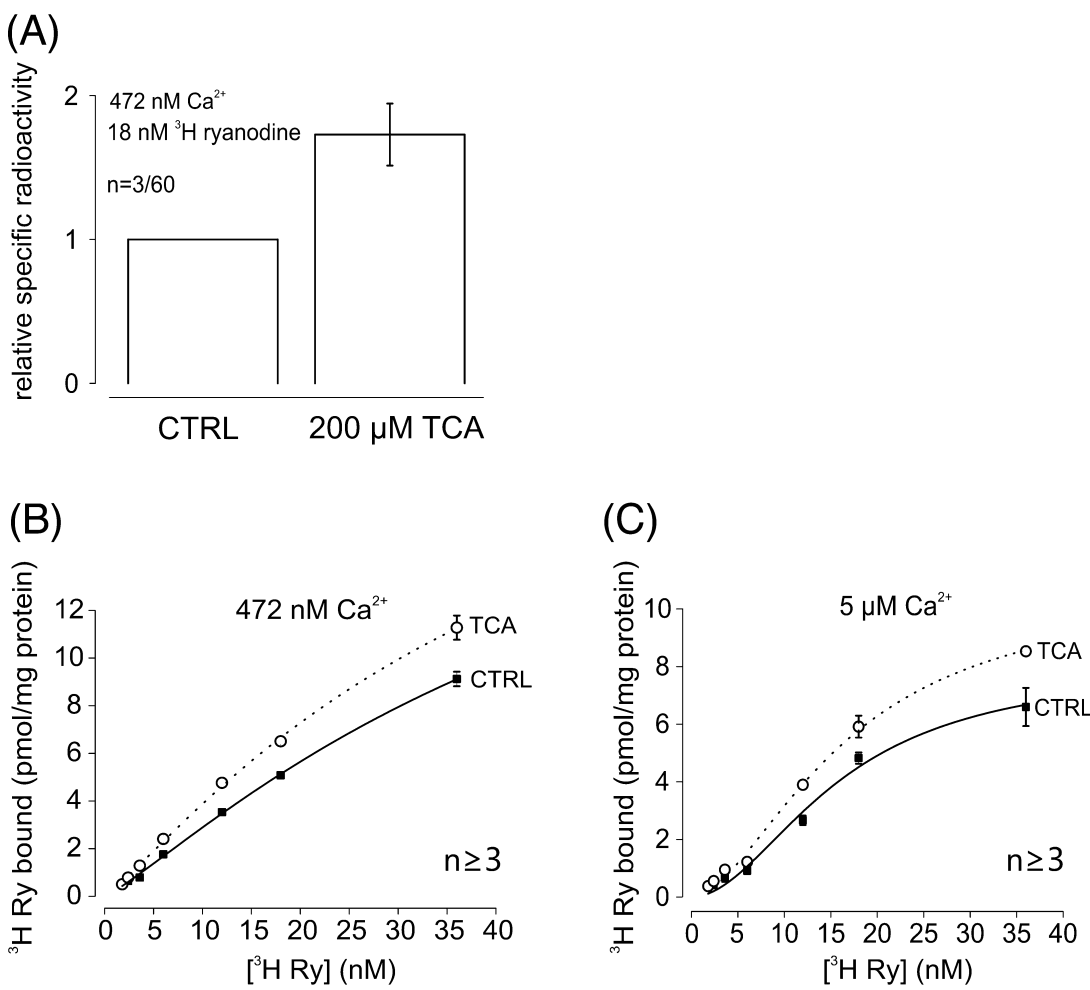

(D)

(E)
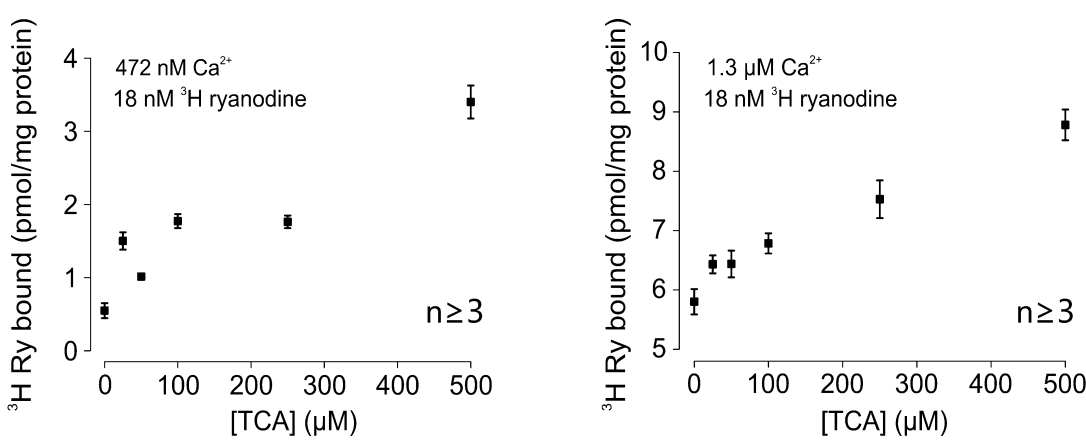

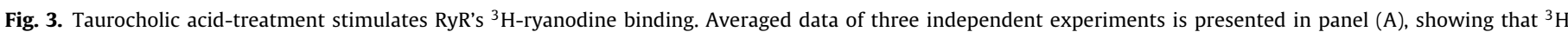

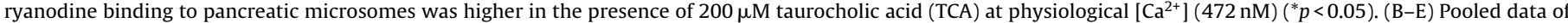

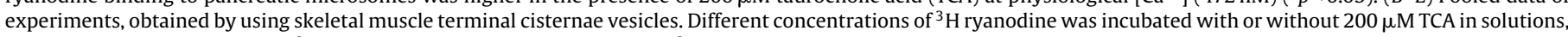

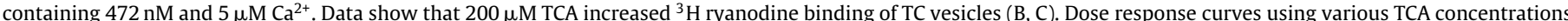

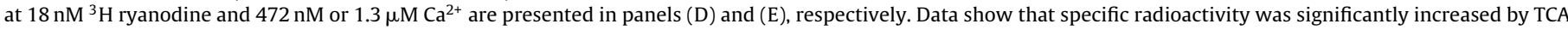
in the 25-500 $\mu \mathrm{M}$ range. TCA: taurocholic acid.

detergent-properties of the bile acid. However, these measurements do not directly confirm whether the binding site for TCA is on the RyR itself, or it is on a closely associated regulatory protein.

\subsection{TCA enhances RyR gating by increasing its open probability and mean open time}

To investigate TCA's effect on RyR channels free of associated proteins, RyRs were solubilized from TC vesicles and purified on sucrose gradient, because most of the RyR's associated counterparts are believed to be lost during this procedure. In order to get deeper insights into the mechanism of action of TCA on RyR channel gating, the purified channels were reconstituted into artificial lipid bilayers and single channel currents were recorded under voltage clamp conditions at $+60 \mathrm{mV}$ membrane potential. Fusion of single RyR channels was initiated at $50 \mu \mathrm{M}\left[\mathrm{Ca}^{2+}\right]$ on either side of the bilayer. Then, $\left[\mathrm{Ca}^{2+}\right]$ on the cytoplasmic side was lowered to $270 \mathrm{nM}$. The top trace in Fig. 5A presents a representative $3 \mathrm{~s}$ long segment of the single channel current recording. Under these conditions the open events were detected as positive (upward) deflections and the channel displayed low open probability (Po) of 0.025 for a $\sim 20 \mathrm{~s}$ record. When TCA was added in increasing concentrations to the cytoplasmic face of the RyR, Po and mean open time $(\tau)$ of the channel increased, which was a consistent finding (Fig. 5A). The average Po and $\tau$ of three independent experiments showed saturating concentration dependence, increasing Po several fold at $500 \mu \mathrm{M}$ TCA (Fig. 5B and C). The half effective concentration was $181.2 \pm 56.6 \mu \mathrm{M}\left(n_{\mathrm{Hill}}=1.54 \pm 0.42\right)$. These data strongly suggest that TCA acts on the RyR protein itself too, and significantly stimulates RyR gating below the pathophysiologically relevant concentration range by increasing both the number and duration of channel openings. The conductance of the channel was not modified by TCA. Finally, the addition of ryanodine caused the characteristic transition to a half-conducting state, implying that 
(A)

(B)
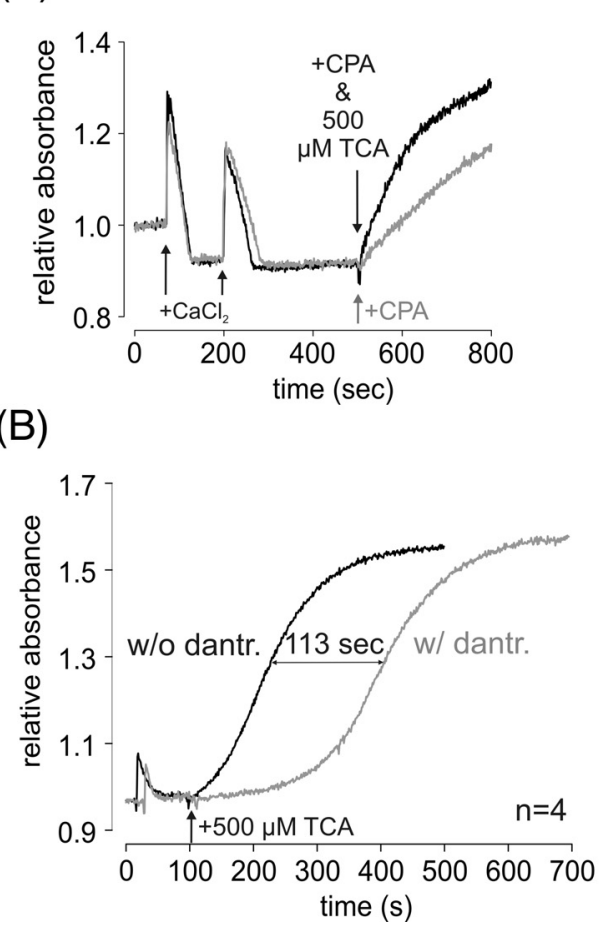

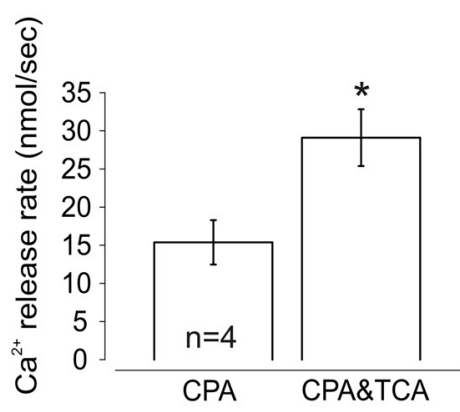

(C)

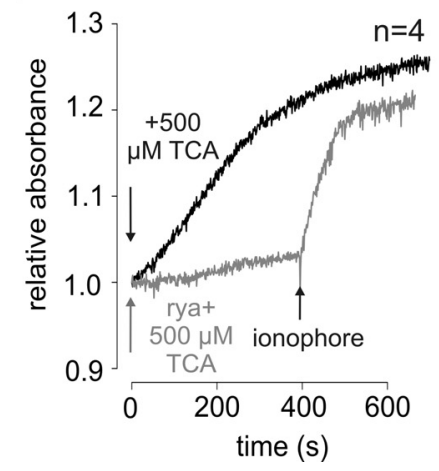

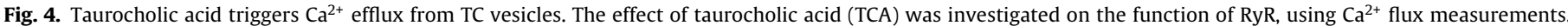

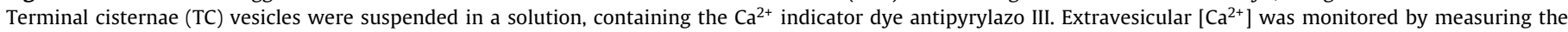

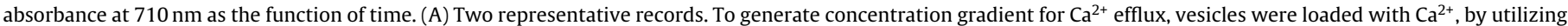

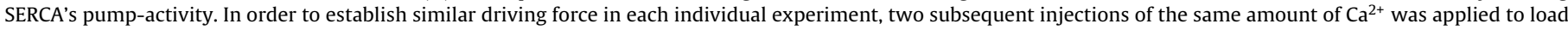

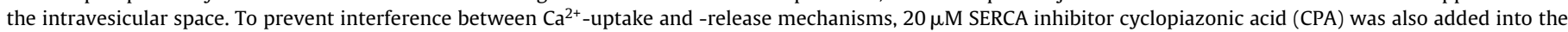

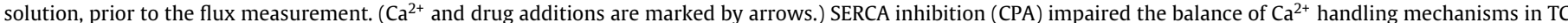

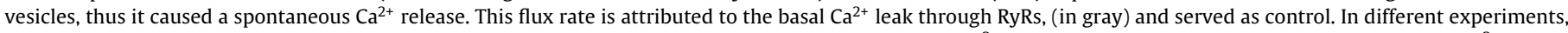

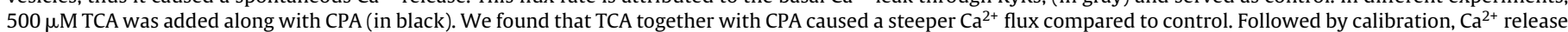

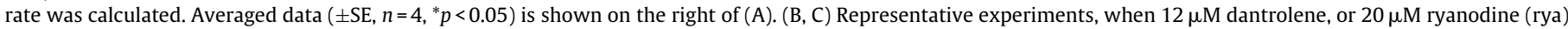

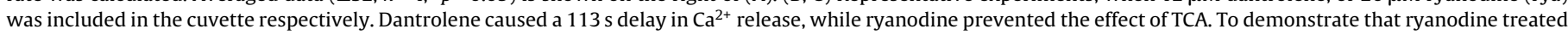

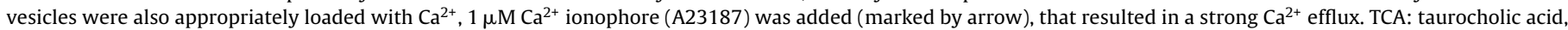
TC: terminal cisternae, CPA: cyclopiazonic acid, rya: ryanodine.

the pharmacological properties of RyR are retained after TCA treatment and ryanodine's and TCA's binding sites are distinct.

\subsection{TDC and TLCS also cause $\mathrm{Ca}^{2+}$ release in pancreatic acinar cells and from TC vesicles}

Because the effective $2-5 \mathrm{mM}$ bile acid concentration might not be reached during bile duct obstruction in the pancreas, other bile acids were also investigated to confirm our basic observations made using TCA. As TLCS and TDC are also often used to investigate bile acid induced changes in the exocrine pancreas $[4,5,12]$, we performed $\mathrm{Ca}^{2+}$ imaging and $\mathrm{Ca}^{2+}$ release experiments using these bile acids too. These results demonstrate that TLCS's and TDC's effect is qualitatively very similar to that we have observed for TCA. Representative experiments are shown in Fig. 6. Notably, TLCS and TDC worked even more potently compared to TCA, in as low as $1 \mathrm{mM}$ (TDC) and $250 \mu \mathrm{M}$ (TLCS) concentrations in intact acinar cells and in $100 \mu \mathrm{M}$ and $50 \mu \mathrm{M}$ on TC vesicles, respectively. Furthermore, TLCS-induced $\mathrm{Ca}^{2+}$ release developed much earlier when compared to $\mathrm{Ca}^{2+}$ signals triggered by TCA as the peak latency was $194 \pm 5 \mathrm{~s}$ for TCA, $195 \pm 12 \mathrm{~s}$ for TDC, and $49 \pm 3 \mathrm{~s}$ for TLCS. These results suggest that the effect of bile acids on RyR is universal. In few experiments the cells were perfused with $250 \mu \mathrm{M}$ TLCS in a $\mathrm{Ca}^{2+}$ free saline for prolonged period ( $9 \mathrm{~min}$, Fig. 6B), which induced oscillating $\left[\mathrm{Ca}^{2+}\right]$ i signals. This pattern is very similar to the one triggered by $5 \mathrm{mM}$ TCA (Fig. 1). At the end of these experiments, $2 \mu \mathrm{M}$ carbachol was immediately added after TLCS treatment, while in the experiment shown in Fig. 6A, TLCS was applied for only $3 \mathrm{~min}$ and TLCS was washed out before carbachol was added. The carbachol-responses in the two cases were very different: they were significantly lower and returned slower in the latter case, when TLCS was applied for $9 \mathrm{~min}$ and was not washed out before carbachol. (B). $\mathrm{Ca}^{2+}$-depletion of the ER (smaller driving force) due to the repetitive $\mathrm{Ca}^{2+}$ release events could account for the smaller amplitude, while the slower $\mathrm{Ca}^{2+}$ clearance can be explained by lower $\mathrm{Ca}^{2+}$ pump (SERCA and/or PMCA) activities. The amplitude and the spatio-temporal characteristics of a $\mathrm{Ca}^{2+}$ signal is ultimately determined by the relative rate of $\mathrm{Ca}^{2+}$ release and $\mathrm{Ca}^{2+}$ elimination mechanisms. Therefore, suppressed $\mathrm{Ca}^{2+}$ reuptake should result in enhanced and long lasting $\mathrm{Ca}^{2+}$ release events and resting $\mathrm{Ca}^{2+}$ leak, which might also significantly contribute to $\mathrm{Ca}^{2+}$ overload in pancreatic acinar cells. However, enhanced ATP expenditure of $\mathrm{Ca}^{2+}$ elimination and mitochondrial depolarization during oscillatory $\mathrm{Ca}^{2+}$ signals could lead to severe ATP depletion and suppressed $\mathrm{Ca}^{2+}$ pump activity, inhibitory action of bile acids on SERCA might also contribute to the slow clearance rate [26-30].

\subsection{TCA inhibits SERCA activity of LSR microsomes}

Then, experiments were designed to test the idea that TLCS's and TCA's inhibitory action on the SERCA pump is partially responsible for the $\mathrm{Ca}^{2+}$ overload during bile acid induced $\mathrm{Ca}^{2+}$ release. SERCA pump's hydrolytic activity was measured using a coupled enzyme-NADH assay and LSR, because this skeletal muscle 
(A)

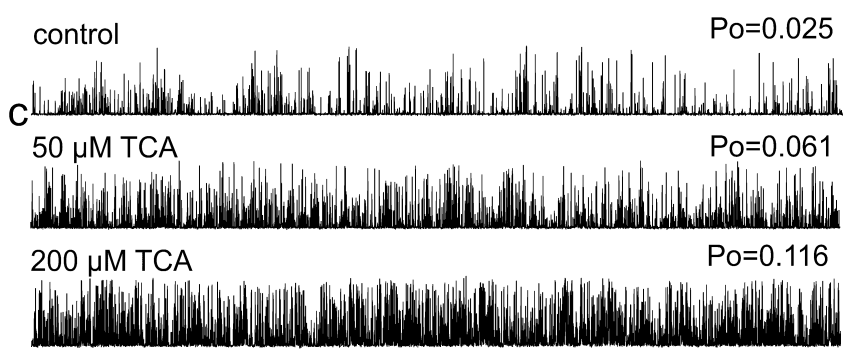

+ ryanodine

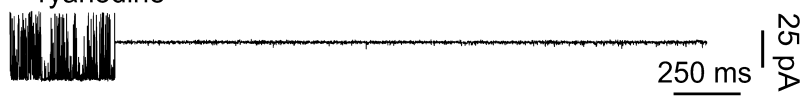

(B)

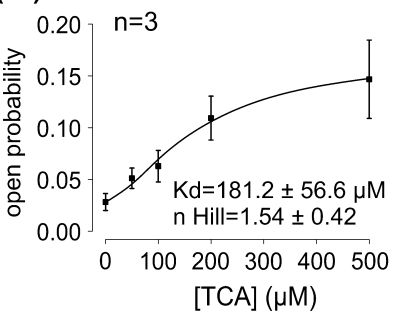

(C)

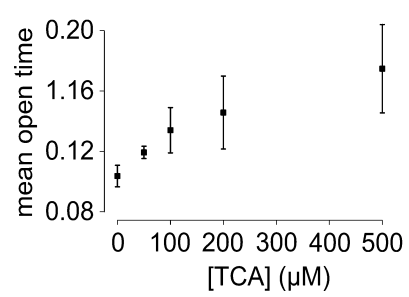

Fig. 5. Taurocholic acid promotes RyR1 gating. Single RyR1 channels were reconstituted into lipid bilayers, and current traces were recorded under voltage clamp conditions, at $+60 \mathrm{mV}$ membrane potential. Representative single channel current traces, recorded under control conditions $\left(270 \mathrm{nM} \mathrm{Ca}^{2+}\right)$ and after taurocholic acid (TCA) was added to the cytoplasmic side of the channel are shown in (A). The closed state level is marked by " $C$ ". Single openings of the channel are represented by upward deflections. Under control conditions, due to the relatively low $\left[\mathrm{Ca}^{2+}\right]$, the channel stayed mostly in closed state. After TCA treatment, the channel opened more frequently. Detailed data analysis revealed that TCA increased both RyR's open probability (Po) and mean open time, as shown by the graphs in (B) and (C) respectively $(n=3)$. The apparent dissociation constant was $181.2 \pm 56.6 \mu \mathrm{M}$. TCA: taurocholic acid.

vesicular fraction is the richest in SERCA. Graphs in Fig. 7A illustrate original records of these experiments, with increasing concentrations of TCA. Smaller slopes at gradually higher TCA concentrations represent lower SERCA ATPase activities. The specific $\mathrm{Ca}^{2+}$-ATPase activity was identified as the portion of total hydrolytic activity, which was inhibited by $10 \mu \mathrm{M}$ cyclopiazonic acid. During analysis, hydrolytic activity was calculated from the slopes and the averaged data of 3-5 independent experiments are shown in Fig. 7A, on the right. These results demonstrate that TCA and TLCS exert an inhibitory action on SERCA's hydrolytic activity and they are in agreement with results published previously [13].

The findings obtained by coupled enzyme assay have also been verified by using a different approach, when SERCA's activity was assessed by determining the $\mathrm{Ca}^{2+}$ uptake rate of LSR vesicles. The experimental setup was very similar to the one used in $\mathrm{Ca}^{2+}$ release experiments. Extravesicular $\left[\mathrm{Ca}^{2+}\right]$ was monitored using antipyrylazo III by measuring the absorbance of the $\mathrm{Ca}^{2+}$ indicator. At a certain point extravesicular $\left[\mathrm{Ca}^{2+}\right]$ was suddenly raised by $12.5 \mu \mathrm{M}$. The cuvette contained $250 \mu \mathrm{g}$ protein (LSR)/ml imaging solution. The experiments were performed in the presence of the RyR inhibitor ruthenium red to prevent interference between RyR mediated background $\mathrm{Ca}^{2+}$ efflux and $\mathrm{Ca}^{2+}$ uptake. $\mathrm{Ca}^{2+}$ uptake rate was calculated using the slope of the best linear fit for the data points. Quantitative data analysis show, that $\mathrm{Ca}^{2+}$ uptake rate was significantly lower in the presence of $250 \mu \mathrm{M}$ TCA, compared to control $(9.57 \pm 0.39$ vs. $6.75 \pm 0.64 \mathrm{nmol}$ $\left.\mathrm{Ca}^{2+} / \mathrm{s}\right)$.

Next, to test the effect of TCA on the $\mathrm{Ca}^{2+}$ removal mechanisms in native pancreatic acinar cells, $\mathrm{Ca}^{2+}$ release was triggered by using
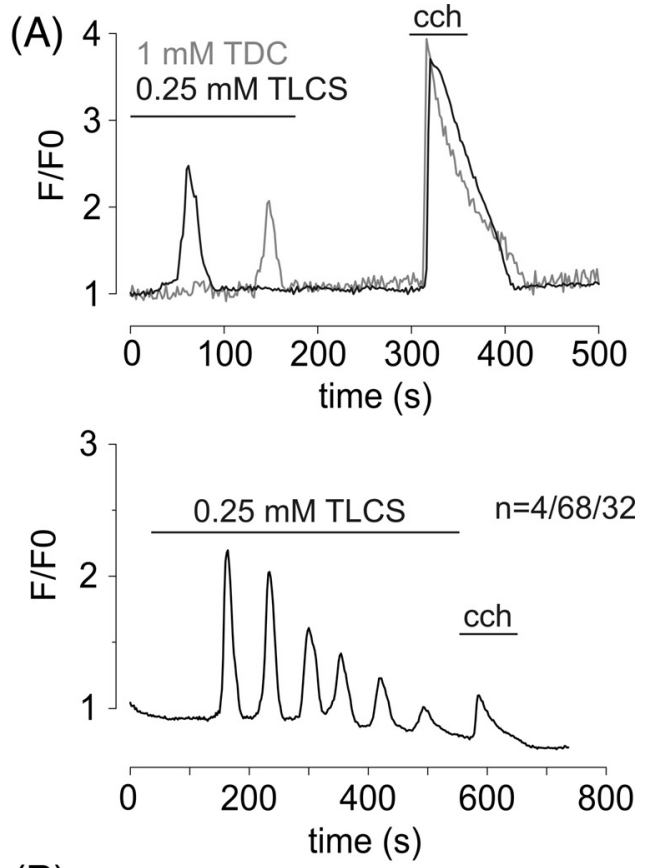

(B)

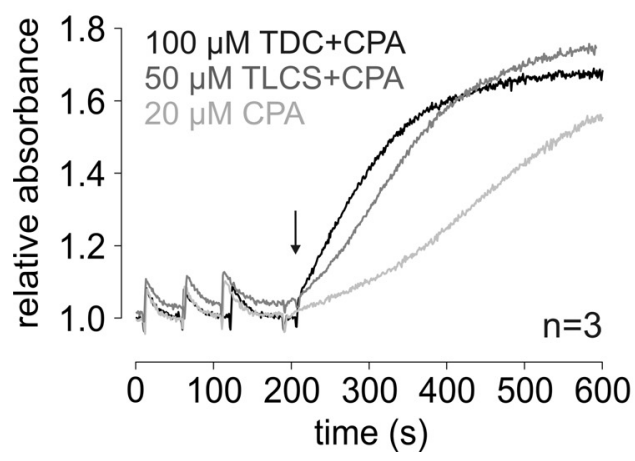

Fig. 6. Tauro deoxicholate and taurolithocholic acid sulphate induces $\mathrm{Ca}^{2+}$ release in intact pancreatic acinar cells and from TC vesicles. Bile acids tauro deoxicholate (TDC) and taurolithocholic acid sulphate (TLCS) were tested using the approaches detailed above. $\mathrm{Ca}^{2+}$ imaging data of two cells treated with $1 \mathrm{mM}$ TDC (gray) or $0.25 \mathrm{mM}$ TLCS (black) are displayed in (A). Both bile acids triggered robust $\mathrm{Ca}^{2+}$ release in the acinar cells in these concentrations. Interestingly, the TLCS-related response developed earlier compared to TDC and TCA-induced $\mathrm{Ca}^{2+}$ signals. The average peak latency was $49 \pm 3,195 \pm 12$ and $194 \pm 5 \mathrm{~s}$, respectively. At the end of all experiments, $2 \mu \mathrm{M}$ carbachol (cch) was applied to test the functionality of the cells. (B) An example of repetitive $\mathrm{Ca}^{2+}$ spikes of a cell treated with $250 \mu \mathrm{M}$ TLCS for prolonged period ( $9 \mathrm{~min}$ ) in a $\mathrm{Ca}^{2+}$-free medium. (C) Representative records of $\mathrm{Ca}^{2+}$ release experiments using terminal cisternae (TC) vesicles. They present that $100 \mu \mathrm{M}$ TDC (gray line) and $50 \mu \mathrm{M}$ TLCS (in black) triggered a stronger $\mathrm{Ca}^{2+}$ efflux compared to the release elicited by cyclopiazonic acid (CPA) only (arrow). Thus, these results demonstrate that TDC and TLCS are also effective $\mathrm{Ca}^{2+}$ releasing bile acids, with RyR1 activating abilities. TDC: tauro deoxicholate, TLCS: taurolithocholic acid sulphate, CPA: cyclopiazonic acid.

$2 \mu \mathrm{M}$ cch, under control conditions and in the presence of $250 \mu \mathrm{M}$ TCA or $100 \mu \mathrm{M}$ TLCS respectively. We chose to apply these bile acid concentrations, because they failed to induce $\mathrm{Ca}^{2+}$ release in acinar cells, but caused significant inhibition of SERCA pump hydrolytic activity. $\mathrm{Ca}^{2+}$ elimination rate was evaluated by measuring the full widths at half maximum (FWHM) of the fluorescence change after carbachol treatment. While carbachol transients' amplitude was not significantly different between the two groups, $\mathrm{Ca}^{2+}$ removal was quicker in cells treated with the bile acids compared to control, as suggested by smaller FWHM values $(61.8 \pm 2.3 \mathrm{~s}$ vs. $95.4 \pm 5.1 \mathrm{~s}$ for TCA, data not shown). Because we did not observe SERCA activation at any bile acid concentration, these data suggest that 

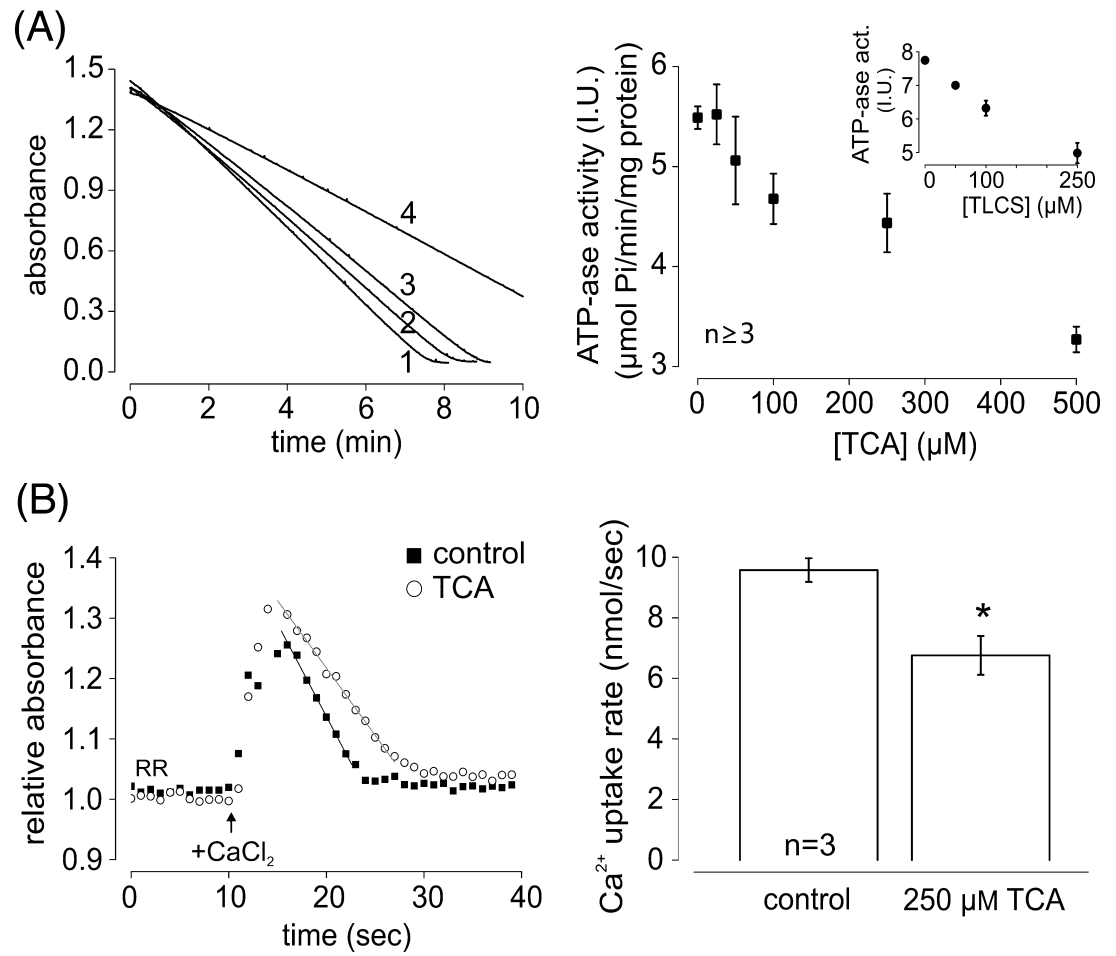

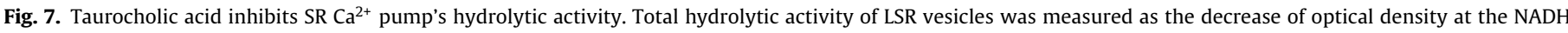

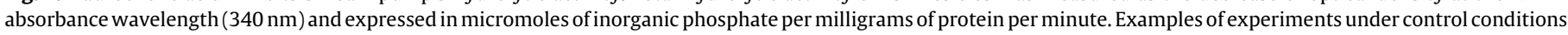

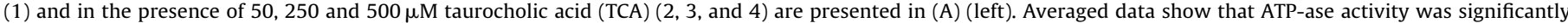

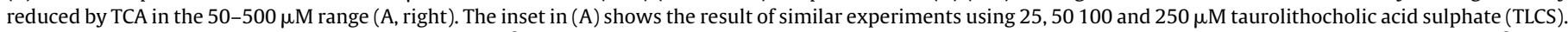

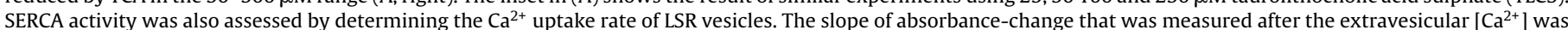

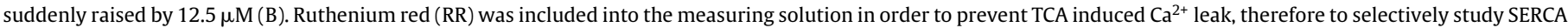

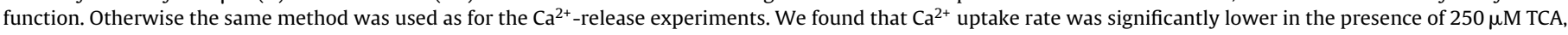

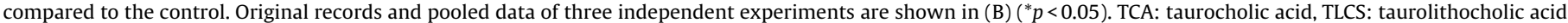
sulphate, RR: ruthenium red.

bile acids also influence other $\mathrm{Ca}^{2+}$ handling proteins. We also performed experiments using $2 \mathrm{mM} \mathrm{TCA}$ (for $3 \mathrm{~min}$ ), which resulted in qualitatively same results (data not shown), suggesting that the bile acid does not contribute to the magnitude of $\mathrm{Ca}^{2+}$ release by inhibiting SERCA activity in acinar cells, or that these bile acid concentrations are not high enough (or applied for long enough) to reach effective concentrations in the cytoplasm. Therefore, we performed similar experiments using carbachol-stimulation, followed by $250 \mu \mathrm{M}$ TLCS treatment for 9 min (see Fig. 6B). Control cells were stimulated only with carbachol. Because cells treated with $250 \mu \mathrm{M}$ TLCS developed $\left[\mathrm{Ca}^{2+}\right]$ oscillations and significantly smaller carbachol response (possibly due to their lower ER $\left[\mathrm{Ca}^{2+}\right]$ and poor ATP-status (also see Section 3.5)), the untreated cells did not serve as adequate controls any more. Therefore, analysis and comparison of $\mathrm{Ca}^{2+}$ clearance rates in the presence or absence of $250 \mu \mathrm{M}$ TLCS cannot be performed. In summary, bile acids inhibit SERCA activity directly, and indirectly, by $\mathrm{Ca}^{2+}$ release induced ATP depletion, but their significance is technically difficult to evaluate in native acinar cells.

\section{Discussion}

The action of bile acids with particular interest to the effect of TLCS have been recently intensively investigated on pancreatic acinar cell's intracellular $\mathrm{Ca}^{2+}$ signaling and cytotoxicity. Cytotoxicity is related to the lipid solubility of the particular bile acid. In general, dehydroxylated and deconjugated bile acids are more toxic than others [31]. The bile mostly contains taurin- or glycin-conjugated secondary (dehydroxylated) bile acids. TCA is one of the most abundant secondary bile acid constituent of the bile. The three most extensively investigated bile acids in the order of cytotoxicity are TLCS $>$ TDC $>$ TCA [5].

Bile acids attracted much attention after the link between persistent elevation of intraacinar $\left[\mathrm{Ca}^{2+}\right]$ and pancreatitis has been established and TCA was demonstrated to trigger excessive $\mathrm{Ca}^{2+}$ release from intracellular stores in pancreatic acinar cells. TCA and TLCS were previously shown to most probably activate $\mathrm{IP}_{3} \mathrm{Rs}$ $[4,5,12]$. Although, the enrollment of RyRs during the process was quite obvious, the way they were recruited was not completely understood. Our study addressed the question for the first time, whether bile acids release $\mathrm{Ca}^{2+}$ by activating RyR. We hypothesized that they directly activate the channel. The objective of our study was to test the action of bile acids on the calcium release channel using direct methods and to assess its significance in impaired $\mathrm{Ca}^{2+}$ signaling.

The data presented here clearly show that bile acids potently and directly open the channel. They thus highlight the role of RyR in bile acid-induced toxic $\mathrm{Ca}^{2+}$ release and propose that the contribution of RyR is direct and cannot only be through the CICR mechanism. Although, bile acid-induced $\mathrm{Ca}^{2+}$ release is initiated from the luminal end of ER, where $\mathrm{IP}_{3} \mathrm{Rs}$ are localized at higher density than RyRs, our study raises the possibility that the pathological process is initiated by RyR activation. Although, answering these questions needs further investigations.

Recent studies have shown that $5-50 \mathrm{mg} / \mathrm{kg}$ dantrolene mitigated caerulein-induced pancreatitis in vivo in mice and suggested dantrolene in the therapy of acute pancreatitis [11]. Therefore, we aimed to assess the role of RyR in TCA-triggered $\mathrm{Ca}^{2+}$ release using dantrolene in live cell $\mathrm{Ca}^{2+}$ imaging experiments. 
Dantrolene is the only RyR antagonist in human medicine, which is used as a muscle relaxant to treat malignant hyperthermia and muscle spasticity caused by stroke, spinal cord injury or multiple sclerosis. One of the most important finding of the present study is that $\mathrm{Ca}^{2+}$ release was significantly attenuated by the drug. Since dantrolene is selective for the skeletal muscle type RyR1 [24], these results provide evidence that the most important isoform involved in bile acid-induced $\mathrm{Ca}^{2+}$ release is RyR1. We used dantrolene in the concentration of $12 \mu \mathrm{M}$, because our group has previously shown that this concentration is sufficient to significantly suppress $\mathrm{Ca}^{2+}$ efflux rate and the amount of $\mathrm{Ca}^{2+}$ released from TC vesicles by thymol [31]. Interestingly, dantrolene inhibited the TCA-induced $\mathrm{Ca}^{2+}$ release by causing a delay in $\mathrm{Ca}^{2+}$ release instead of inhibiting $\mathrm{Ca}^{2+}$ flux rate. The dissimilarity of these data possibly due to the idea that dantrolene probably act on or requires a yet unidentified accessory protein. This is supported by dantrolene's ineffectiveness on solubilized RyR channel currents [32]. Importantly though, ryanodine treatment completely abolished the effect of TCA, which argues against the ionophoretic theory of bile acid action [25] and confirms the specificity of TCA's action on the RyR protein complex.

The most important result of this study is provided by our single channel current data. In these experiments, purified RyRs, - free of most of the accessory proteins - were incorporated into artificial lipid bilayers. They provide clear evidence that TCA directly acts on the RyR protein itself, most probably without modifying the interactions between RyR and its regulatory proteins. The fact that TCA's effect developed and reached steady state quickly after addition, implies that RyR activation does not rely on nonspecific mechanisms, such as TCA's detergent properties and increased membrane fluidity, which could have been be due to the progressive accumulation of the bile acid in the bilayer.

Earlier studies have demonstrated that bile acids slow down $\mathrm{Ca}^{2+}$ clearance rate by inhibiting SERCA pump activity in stimulated pancreatic acinar cells. By doing so, they chronically deplete $\mathrm{Ca}^{2+}$ stores, activate store-operated $\mathrm{Ca}^{2+}$ entry that cause $\mathrm{Ca}^{2+}$ overload and cell death. In these experiments a bile acid mixture was used; but the effects of the components were not investigated specifically [13]. Therefore, we aimed to specify the action of TCA and TLCS on SERCA pump activity. Although, these bile acids significantly inhibited SERCA pump activity in LSR vesicles, they failed to decrease $\mathrm{Ca}^{2+}$ elimination rate in native acinar cells in relatively low concentrations ( $250 \mu \mathrm{M}$ TCA and $100 \mu \mathrm{M}$ TLCS). Instead, they slightly enhanced $\mathrm{Ca}^{2+}$ removal rate. This discrepancy suggests that the SERCA-inhibiting action might be masked by an unknown mechanism, or that these bile acid concentrations are not high enough or they are not applied for long enough to reach effective concentrations in the cytoplasm. Therefore, $\mathrm{Ca}^{2+}$ clearance rate after carbachol stimulation was evaluated after cells were treated with higher $(250 \mu \mathrm{M})$ TLCS concentration and for more prolonged periods. TLCS at this concentration produces robust $\mathrm{Ca}^{2+}$ oscillation and mitochondrial membrane depolarization, which leads to high rate of ATP consumption by $\mathrm{Ca}^{2+}$ ATPases and interferes with ATP synthesis. As a consequence, $\mathrm{Ca}^{2+}$ depletion of the ER and severe ATP depletion develops, which results in significantly smaller amplitude of carbachol response with slow slope of recovery compared to control. Thus, because this approach to evaluate the effect of bile acids on SERCA pump in native cells is very limited by the above mentioned interfering circumstances, appropriate consequences cannot be drawn. We can only rely on SERCA ATPase activity measurements to assess the effect of bile acids on the $\mathrm{Ca}^{2+}$ pump [26-30].

In summary, our data supports the idea that RyR is allosterically gated by bile acids and RyR is a possible therapeutic target in pancreatitis, furthermore, they emphasize the therapeutic potential of dantrolene.
Although, most of the studies investigating the pathophysiology of acute pancreatitis focused on pancreatic acinar cells, the action of bile acids on ductal cell might be pathologically significant too, because during the biliary reflux bile acids reach the ductal cells first. The effect of bile acids on ductal cells was biphasic. Low concentration of chenodeoxycholic acid (CDC) stimulated $\mathrm{HCO}_{3}{ }^{-}$ secretion in $\mathrm{Ca}^{2+}$ dependent manner, which has a protective effect on the pancreas. In contrast, high concentrations of bile acids induce toxic $\left[\mathrm{Ca}^{2+}\right]$ i elevations, which leads to the loss of mitochondrial membrane potential and ATP depletion. At severely low [ATP] the $\mathrm{Cl}^{-} / \mathrm{HCO}_{3}{ }^{-}$exchanger function is suppressed. As a consequence, low fluid secretion rate favors ductal cell injury and the damage of ductal integrity, thus acute pancreatitis [31,33-36].

\section{Conflict of interest}

None.

\section{Acknowledgements}

This work was supported by a grant provided to IJ and JA from the Hungarian Scientific Research Fund (OTKA K81923 and OTKA PD 112199).

JA is supported by the Janos Bolyai Research Scholarship of the Hungarian Academy of Sciences and the Lajos Szodoray Scholarship of the University of Debrecen, Faculty of Medicine.

\section{References}

[1] D. Yadav, A.B. Lowenfels, The epidemiology of pancreatitis and pancreatic cancer, Gastroenterology 144 (2013) 1252-1261.

[2] E.L. Opie, The etiology of acute hemorrhagic pancreatitis, Johns Hopkins Hosp. Bull. 12 (1901) 182-188.

[3] H.J. Aho, S.M. Koskensalo, T.J. Nevalainen, Experimental pancreatitis in the rat. Sodium taurocholate-induced acute haemorrhagic pancreatitis, Scand. J. Gastroenterol. 15 (1980) 411-416

[4] S.Z. Husain, A.I. Orabi, K.A. Muili, et al., Ryanodine receptors contribute to bile acid induced pathological calcium signaling and pancreatitis in mice, Am. J. Physiol. Gastrointest. Liver Physiol. 302 (2012) 1423-1433.

[5] S. Voronina, R. Longbottom, R. Sutton, O. Petersen, A. Tepikin, Bile acids induce calcium signals in mouse pancreatic acinar cells: implications for bile-induced pancreatic pathology, J. Physiol. 540 (2002) 49-55.

[6] J.V. Gerasimenko, G. Lur, M.W. Sherwood, et al., Pancreatic protease activation by alcohol metabolite depends on $\mathrm{Ca}^{2+}$ release via acid store $\mathrm{IP}_{3}$ receptors, Proc. Natl. Acad. Sci. U. S. A. 106 (2009) 10758-10763.

[7] L.R. Johnson, K.F. Ghishan, D.J. Kaunitz, L.J. Merchant, M.H. Said, D.J. Wood, Physiology of the Gastrointestinal, Tract Academic Press, 2012.

[8] O.H. Petersen, V.A. Tepikin, Polarized calcium signaling in exocrine gland cells Annu. Rev. Physiol. 70 (2007) 273-299.

[9] J.H. Won, W.J. Cottrell, T.H. Foster, D.I. Yule, $\mathrm{Ca}^{2+}$ release dynamics in parotid and pancreatic exocrine acinar cells evoked by spatially limited flash photolysis, Am. J. Physiol. Gastrointest. Liver Physiol. 293 (2007) 1166-1177.

[10] S.Z. Husain, P. Prasad, W.M. Grant, T.R. Kolodecik, M.H. Nathanson, F.S. Gorelick, The ryanodine receptor mediates early zymogen activation in pancreatitis, Proc. Natl. Acad. Sci. U. S. A. 102 (2005) 14386-14391.

[11] A.I. Orabi, A.U.Shah, M.U. Ahmad, et al., Dantrolene mitigates caerulein-induced pancreatitis in vivo in mice, Am. J. Physiol. Gastrointest. Liver Physiol. 299 (2010) 196-204

[12] V.J. Gerasimenko, G.S. Flowerdew, K.T. Voronina, et al., Bile acids induce $\mathrm{Ca}^{2+}$ release from both the endoplasmic reticulum and acidic intracellular calcium stores through activation of inositol trisphosphate receptors and ryanodine receptors, J. Biol. Chem. 281 (2006) 40154-40163.

[13] J.Y. Kim, K.H. Kim, J.A. Lee, et al., Transporter-mediated bile acid uptake causes $\mathrm{Ca}^{2+}$-dependent cell death in rat pancreatic acinar cells, Gastroenterology 122 (2002) 1941-1953

[14] J.A. Williams, M. Korc, R.L. Dormer, Action of secretagogues on a new preparation of functionally intact, isolated pancreatic acini, Am. J. Physiol. 235 (1978) 517-524.

[15] T. Ozawa, Ryanodine-sensitive $\mathrm{Ca}^{2+}$ release mechanism of rat pancreatic acinar cells is modulated by calmodulin, Biochim. Biophys. Acta 1452 (1999) 254-262.

[16] S. Sárközi, J. Almássy, B. Lukács, N. Dobrosi, G. Nagy, I. Jóna, Effect of natura phenol derivatives on skeletal type sarcoplasmic reticulum $\mathrm{Ca}^{2+}$-ATPase and ryanodine receptor, J. Muscle Res. Cell Motil. 28 (2007) 167-174.

[17] X. Altafaj, J. France, J. Almassy, et al., Maurocalcine interacts with the cardiac ryanodine receptor without inducing channel modification, Biochem. J. 406 (2007) 309-315. 
[18] T.J. Lanner, D.K. Georgiou, A. Dagnino-Acosta, et al., AICAR prevents heat induced sudden death in RyR1 mutant mice independent of AMPK activation, Nat. Med. 18 (2012) 244-251.

[19] G.G. Du, J.P. Imredy, D.H. MacLennan, Characterization of recombinant rabbit cardiac and skeletal muscle $\mathrm{Ca}^{2+}$ release channels (ryanodine receptors) with a novel [3H]ryanodine binding assay, J. Biol. Chem. 273 (1998) 33259-33266.

[20] J.M. Dias, C. Szegedi, I. Jóna, P.D. Vogel, Insights into the regulation of the ryanodine receptor: differential effects of $\mathrm{Mg}^{2+}$ and $\mathrm{Ca}^{2+}$ on ATP binding, Biochemistry 45 (2006) 9408-9415.

[21] S. Sárközi, C. Szegedi, B. Lukács, M. Ronjat, I. Jóna, Effect of gadolinium on the ryanodine receptor/sarcoplasmic reticulum calcium release channel of skeletal muscle, FEBS J. 272 (2005) 464-471.

[22] N. Szentandrássy, A. Szabó, J. Almássy, et al., Effects of articaine and ropivacaine on calcium handling and contractility in canine ventricular myocardium, Eur. J. Anaesthesiol. 27 (2010) 153-161.

[23] T.J. Fitzsimmons, I. Gukovsky, J.A. McRoberts, E. Rodriguez, F.A. Lai, S.J. Pandol, Multiple isoforms of the ryanodine receptor are expressed in rat pancreatic acinar cells, Biochem. J. 351 (2000) 265-271.

[24] F. Zhao, P. Li, S.R. Chen, C.F. Louis, B.R. Fruen, Dantrolene inhibition of ryanodine receptor $\mathrm{Ca}^{2+}$ release channels. Molecular mechanism and isoform selectivity, J. Biol. Chem. 276 (2001) 13810-13816.

[25] P. Zimniak, J.M. Little, A. Radominska, D.G. Oelberg, M.S. Anwer, R. Lester, Taurine-conjugated bile acids act as $\mathrm{Ca}^{2+}$ ionophores, Biochemistry 30 (1991) 8598-8604.

[26] J.I. Bruce, Plasma membrane calcium pump regulation by metabolic stress, World J. Biol. Chem. (2010) 221-228.

[27] J.I. Bruce, The Pancreapedia: Exocrine Pancreas Knowledge Base, PMCA (2013), http://dx.doi.org/10.3998/panc.2013.7
[28] D.N. Criddle, J. Murphy, G. Fistetto, et al., Fatty acid ethyl esters cause pancreatic calcium toxicity via inositol trisphosphate receptors and loss of ATP synthesis, Gastroenterology 130 (2006) 781-793.

[29] S.L. Barrow, S.G. Voronina, G. da Silva Xavier, et al., ATP depletion inhibits $\mathrm{Ca}^{2+}$ release, influx and extrusion in pancreatic acinar cells but not pathological $\mathrm{Ca}^{2+}$ responses induced by bile, Pflugers Arch. 455 (2008) 1025-1039.

[30] S.G. Voronina, S.L. Barrow, O.V. Gerasimenko, O.H. Petersen, A.V. Tepikin, Effects of secretagogues and bile acids on mitochondrial membrane potential of pancreatic acinar cells: comparison of different modes of evaluating DeltaPsim, J. Biol. Chem. 279 (2004) 27327-27338.

[31] V.Venglovecz, Z. Rakonczay, P. Hegyi, The effects of bile acids on pancreatic ductal cells, The Pancreapedia: Exocrine Pancreas Knowledge Base (2012), http:// dx.doi.org/10.3998/panc.2012.8

[32] P. Szentesi, C. Collet, S. Sárközi, et al., Effects of dantrolene on steps of excitationcontraction coupling in mammalian skeletal muscle fibers, J. Gen. Physiol. 118 (2001) 355-375

[33] C. Alvarez, A. Fasano, B.L. Bass, Acute effects of bile acids on the pancreatic duct epithelium in vitro, J. Surg. Res. 74 (1998) 43-46.

[34] J. Maléth, V. Venglovecz, Z. Rázga, L. Tiszlavicz, Z. Rakonczay Jr., P. Hegyi, Non-conjugated chenodeoxycholate induces severe mitochondrial damage and inhibits bicarbonate transport in pancreatic duct cells, Gut 60 (2011) $136-138$.

[35] H.A. Reber, J.G. Mosley, The effect of bile salts on the pancreatic duct mucosal barrier, Br. J. Surg. 67 (1980) 59-62.

[36] V. Venglovecz, Z. Rakonczay Jr., B. Ozsvári, T. Takács, J. Lonovics, A. Varró, M.A. Gray, B.E. Argent, P. Hegyi, Effects of bile acids on pancreatic ductal bicarbonate secretion in guinea pig, Gut 57 (2008) 1102-1112. 